\title{
PACIFIC UNIVERSITY COLLEGE OF OPTOMETRY'S EVOLVING HISTORY
}

\author{
Sandhya Shekar, M.S. \\ Vision Science Student \\ Pacific University College \\ of Optometry \\ shek2439@pacificu.edu
}

\section{Karen To, B.S.}

Optometry Student

Pacific University College

of Optometry

to5181@pacificu.edu

10.14434/hindsight.v51i4.31669

\begin{abstract}
The College of Optometry at Pacific University in Oregon began operations in 1945. This paper celebrates the $75^{\text {th }}$ anniversary of Pacific University College of Optometry (PUCO) by discussing its history, its accomplishments, and its current activities.
\end{abstract}

\section{Keywords}

AMIGOS eye care, international optometry, optometric education, optometry history, vision performance institute, vision science graduate program

The arrival of 2020 marks a new decade and a semi sesquicentennial milestone for the College of Optometry at Pacific University. The college celebrates its 75th anniversary amidst an ongoing pandemic (COVID-19). It had been hoped that a gala would be held at the Great Western Council of Optometry Congress 2020 to honor Pacific University for its steadfast dedication to its students, the community and to the advancement of the profession of optometry. The College of Optometry's past is a fascinating story that must be told.

\section{Inception}

In 1921, two optometry schools, DeKeyser Institute of Optometry and the Oregon College of Ocular Sciences merged to form the North Pacific College of Optometry, in Oregon. The college was led by Dr. Harry Lee Fording until 1940, when he transferred the charter of the school to three of his former students, Drs. Newton K. Wesley, Clarence "Clarky" Carkner, and Roy Clunes. Under their guidance, the college remained in operation until the U.S. became involved in World War II. Many of the students were drafted for military service, so as the class numbers dwindled, the college was forced to close its doors in 1942 until further notice.

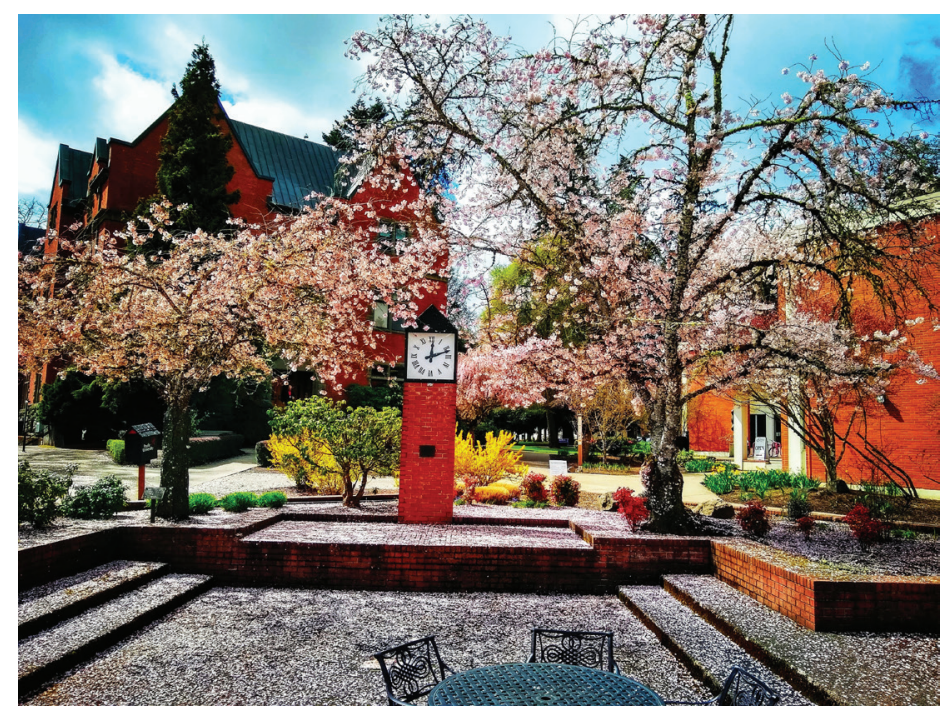

A Pacific University campus scene. Image courtesy Sandhya Shekar.

In 1945, a proposal was made to Pacific University with the aim of reopening the optometry program as a 'College of Optometry' under its affiliation. The Board of Trustees, at the time, saw this as an opportunity for Pacific University to expand its curriculum; on May 22, 1945, PUCO became the ninth fully accredited optometry program to be established in the U.S. With the assistance of Dr. Wesley, it 


\section{ARTICLES ${ }_{S H E K A R A N D} T O$}

became the first university-based program of optometry to recognize the O.D. degree as a post-graduate degree. In becoming a part of Pacific University, the College was able to further develop its curriculum in the basic sciences and its facilities to house its current post-baccalaureate four-year professional graduate degree program. Now, a typical semester during the first two years of the program averages 18 to 22 credits. While the program is scheduled to be completed in four calendar years, the amount of credits required to be awarded the doctor of optometry degree equates to a course load of 5.9 years. ${ }^{2}$

\section{Gargantuan efforts}

In its infancy, the college had its humble beginnings in the basement of Marsh Hall-the administration building of Pacific University. The deans who came and went had to find solutions to lift the understaffed college out of its financial woes. With a sum of $\$ 90,000$ left by a physician alumnus to Pacific University and the efforts of various individuals such as Drs. Clarence Carkner, Roy Clunes, and Raymond Roy Sr., adequate funds were garnered for a new College of Optometry building that was erected in the spring of 1952: the original Jefferson Hall. The Forest Grove Eye clinic established in 1945 was relocated to Jefferson Hall around the same time.

With construction underway, the faculty members worked tirelessly to build the school curriculum. Every faculty member contributed to the courses that were offered such as basic visual sciences, clinical and theoretical courses. The dean at the time, Dr. Richard Feinberg, found himself teaching statistics and occupational vision in addition to his administrative duties. Following his resignation as dean in August 1951, four senior members of the faculty formed a committee to oversee the college administration. Dr. James F. Wahl arrived in the fall of September 1955 to assume the position of dean. His focus was on student enrollment, which at that time had fallen with only nine students graduating in January 1956 and 14 students graduating in the following year.

Another concern of his was in maintaining a reasonably sized faculty at the college. The salary afforded by the college was not substantial but to the faculty who remained, their commitment to the college and its students contributed to its growth and expansion. 'Between 19601980, two eye clinics formed within the County Health Centers in Portland. New eye clinics rose to include the Washington State School for the Blind Eye Clinic and the Portland Eye Clinic, formerly known as the Oregon Optometric Center in 1965 and 1969, respectively. Three more clinics were established in Cornelius, Hillsboro and Beaverton between 1980 and 2011 with improved eye care facilities. ${ }^{3}$ The college continued to blossom with the development of a unique joint master's program with

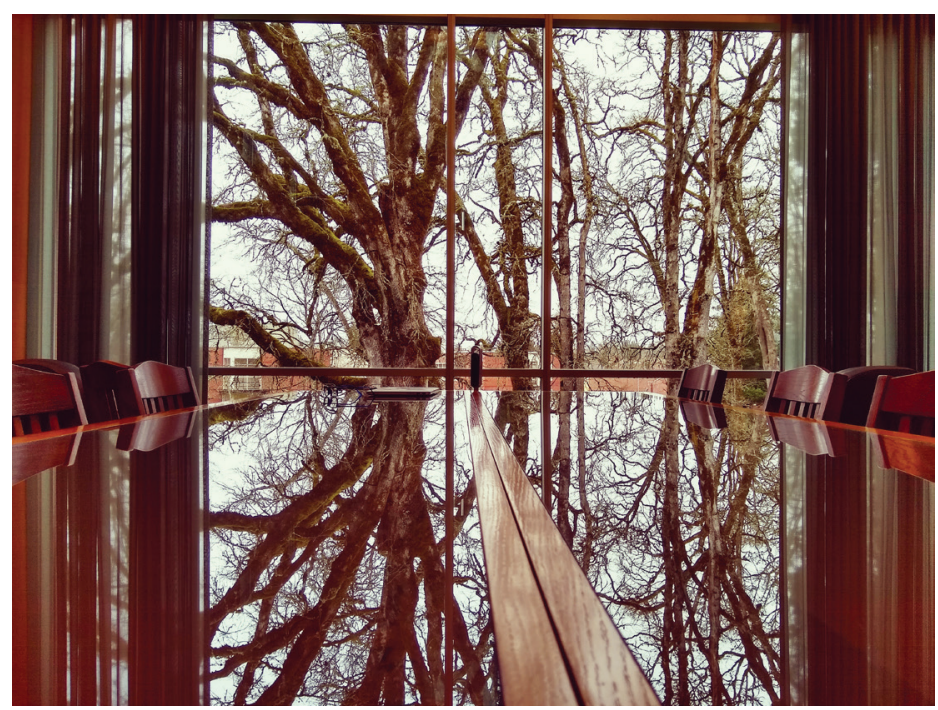

The study area in the Pacific University library overlooking the Jefferson Hall optometry building. Image courtesy Sandhya Shekar.

Pacific's College of Education on the subject of visual function's role in learning in 1983-84. After the state requirements were met, the program became official and the first degree of the program was awarded in $1984{ }^{4}$

\section{Growing into Prominence}

Through the efforts of the college administration and a funded government grant, the clinical curriculum expanded during the 1980s and 1990s. Several liaisons were established and various clinical training sites were opened in partnership with the Veteran's Administration Medical Centers, community health centers, and treatment centers managed by the U.S. Armed Services, U.S. Public Health Service, and the Indian Health Service. ${ }^{2}$ Today, the College of Optometry has 39 full-time and 10 part-time faculty members and close to 400 students pursuing various optometry and vision science degrees. ${ }^{5}$ The college is accredited by the American Council of Optometric Education and graduates practice in all 50 states, seven foreign countries and all branches of the Uniformed Services. ${ }^{3}$ It still remains as the only professional doctoral program in vision care education and training in the Pacific Northwest. The college is home to students from over 40 states (including the Midwest) in the U.S., western provinces of Canada, India, China, Taiwan, the United Arab Emirates and several other countries.

\section{Improved clinical education}

The college now operates six clinical centers that offer a wide breadth of educational opportunities in primary care and specialty services that include ocular disease, binocular vision disorders, occupational vision, pediatrics, contact lenses and low vision. This also includes specialties such as three-dimensional vision and diplopia clinic, vision therapy, sports vision, neuro-ophthalmic disease, traumatic brain 
injury rehabilitation, etc. with state-of-the-art diagnostic facilities. Residency programs that include cornea and contact lenses, ocular disease, and vision therapy and rehabilitation are offered by the college and its affiliates.

The college's curriculum undergoes constant reconstruction to reflect the expanding scope of practice of optometry. In the 1980s, a course in YAG laser application was introduced and taught by distinguished optometry faculty member, Dr. Nada Lingel. The college later decided to add a hands-on laser-specific elective course in 2019 to enhance the third-year curriculum. A unanimous approval from the optometry faculty has instated the elective course as a part of the core curriculum for this year. In this newly approved special topics course, students receive hands-on instruction with state-of-the-art laser systems so that they're equipped to perform at the peak of their scope of practice in various states in the country. ${ }^{6}$

The College of Optometry also maintains interprofessional liaisons with other branches of health sciences at Pacific University. A Balance Clinic was established with the help of Dr. Bradley Coffey, College of Optometry; Dr. Katie Farrell, College of Physical Therapy; and Dr. Anne Hogan, School of Audiology in 2013-14. Today, students from the college embark on externships at eye care facilities in over 100 different locations across North America including Pacific University Eye Clinics in Oregon, as a part of their clinical rotations.

\section{Community Eye Care}

Pacific Eye Clinics at Forest Grove, Cornelius, and Hillsboro are postured to provide care for patients from underserved communities. Some of these clinics share facilities with Virginia Garcia Health Centers (VGC) and also offer free/lowcost diabetic eye screening on certain days for VGC patients.

To expand its reach to other underserved and lowincome communities, an optometry community outreach program was established and is now managed by its director, Dr. Jamy Borbidge. Students have the opportunity to participate in over 100 events that are scheduled throughout the year by the outreach team. The students contribute over 3,000 hours annually in pediatric vision screenings and comprehensive dilated screenings utilizing the college's mobile vision clinic, the EyeVan. The mobile clinic has traveled to sites that include churches, homeless shelters, and migrant camps in the Portland metro area to offer eye care services since 2003.8,9

In 2018, the college was recognized as the "School of the Year" by the National Optometric Association for its unwavering commitment to building a diverse community. ${ }^{10}$ Dr. Borbidge expresses her gratitude in working alongside optometry students and community partners through the Outreach Program, noting that "it is rewarding to not only teach our students clinical skills but also about access to eye care issues and how to provide culturally competent healthcare." In association with the college's Vision Optometric Services to Humanity (VOSH) international chapter known as AMIGOS Eye Care, the outreach team has planned trips to eastern Oregon where students have been able to provide essential eye care to the communities there, including Native Americans.

International vision service trips are coordinated every year by AMIGOS Eye Care, a non-profit organization that was established in 1975 at the college. Students and faculty participate in trips to countries such as Guatemala, Senegal, and China to provide vision care, including glasses to areas that have little to no access to eye care. Over the years, AMIGOS has provided over 40,000 pairs of eyeglasses to those in need and are instrumental to the diagnosis and treatment of eye disease. ${ }^{11}$ Dr. Scott Pike, who serves on the teaching faculty and is a PUCO alumnus himself and who has been involved with AMIGOS since the nineties, shared that "I loved optometry but the work I was doing in Guatemala was more like what I was supposed to be doing; AMIGOS has allowed me to be more involved in the collaborations between the school and my own non-profit."

\section{Research and Development}

The College of Optometry has become a respected leader in research and practice over the years. The college offered a master's degree in the early 1950s, with the projects primarily focused on clinical research and physiological optics. Establishment of the Vision Performance Institute (VPI) at the Forest Grove campus in 2006 opened doors to ergonomics, human factors and industrial research projects. VPI was established by Dr. Jim Sheedy when he moved from The Ohio State University to take up the position of academic dean in 2006. Much of the research conducted at VPI is funded by Fortune 500 companies, and ophthalmic and pharmaceutical industries. The research projects span across topics such as human performance on varied digital displays, eye tracking, visual ergonomics, and virtual reality. These projects are executed with the help of students from the vision science program, the optometry program and other undergraduate programs under the supervision of research scholars and senior researchers. VPI also held seven annual research conferences in its premises from 2007 to 2014 to encourage new industry collaborations and served as a platform for researchers to share their work.

With a plethora of experienced faculty, the college also has students conduct research in the fields of binocular vision, vision therapy, neuroscience, visual perception, sports vision and contact lenses. The contact lens clinic at Forest Grove has faculty and graduate students conducting research in the field of soft, rigid and scleral lenses along with several myopia control studies. Prof. Patrick J. Caroline, associate professor at Pacific University, in coalition with his 
contact lens peers, established the Contact Lens Museum to display their vintage collection of several contact lens artifacts, instruments and publications next to the College of Optometry in 2019.12 The College of Optometry is also part of a multi-center Childhood Atropine for Myopia Progression (CHAMP) study to examine a new treatment to slow the progression of myopia. ${ }^{13}$

\section{Vision Sciences Program}

The College of Optometry offers M.S. and Ph.D. degrees in vision sciences. The Master of Science (M.S.) program was established in 1950, during which the focus was primarily on physiological optics and clinical optometry. Between the 1950s and the 1990s, a total of 52 students graduated with a M.S. degree in vision science or clinical optometry. ${ }^{14}$ After undergoing major curriculum changes which came into existence in 2014, the program now encompasses topics relating to contemporary vision science research such as human performance, visual ergonomics, and sports vision. The College of Optometry established its first Ph.D. program in 2016, becoming the second program to initiate a Ph.D. degree at Pacific University. The Vision Science program includes graduate and optometry students, both local and international, interested in pursuing a research degree. Sixtyseven M.S. students and two Ph.D. students have graduated from the vision sciences program after the implementation of the revised curriculum. ${ }^{12}$

\section{International Coalition}

The College of Optometry has ties with other optometric colleges, universities and clinical training sites in the U.S. and worldwide, including China, Taiwan, Japan, South Korea and Germany. The year 1987 marked the first international coalition with Kikuchi College of Optometry in Japan. Dr. Shinji Seki, an alumnus of PUCO and former President of Kikuchi College expressed a desire to advance optometric education and enhance the art of practice of optometry in Japan through collaborations. Since then, several students from Japan have graduated with doctor of optometry or M.S. degrees from PUCO. Aalen University in Germany began its collaboration with PUCO in the early 2000s in the hopes of providing better clinical education to their students in the fields of binocular vision, vision therapy, sports vision and pediatrics. Faculty from PUCO often visit the university to teach courses and also welcome exchange graduate students to spend a semester at the Forest Grove Campus.

The College of Optometry has also established connections with eye hospitals in China and Taiwan to offer exchange opportunities for practitioners. In 2017, PUCO conceptualized and designed a 11-month undergraduate clinical program, Bachelor of Applied Vision Sciences, for students from China and Taiwan at the Forest Grove campus. The program kick-started in 2019 to provide these students with international optometric experiences especially in contact lenses, myopia control, vision therapy, pediatric optometry and visual rehabilitation. These students will later work in parallel with ophthalmologists in their respective countries to provide primary eye care and specialty services.

PUCO also offers advanced vision science workshops for practitioners from China in the fields of clinic management, specialty contact lens, myopia control, vision therapy for problems related to learning disabilities, binocular and recreational vision training, and pediatric eye care. ${ }^{15}$

\section{Continuing Education Programs}

Another avenue that the college uses to share expertise is the continuing education program that allows doctors to stay knowledgeable in their growing field. The college manages the Island Eyes Conference that takes place every year in Hawaii, providing over 30 hours of continuing education (CE) credit. The Glaucoma Symposium is another annual event that is hosted by the college for doctors to learn about the latest advancements in diagnostic tools, medication and surgery to best treat glaucoma (2021). The college also organizes seminars and talks by esteemed faculty members, researchers and professionals from other universities, labs and industries. Doctors and students attending these sessions can learn from the best in the field and receive CE credits.

\section{Student-Faculty Relationship}

The college prides itself in nurturing student-faculty relationships. Faculty and staff play a role in facilitating an inclusive environment where students can learn, and freely share their thoughts in a class setting. A mentor program was launched recently as a means to support the students at the college. Each faculty member serves as a guide to a few students should they need any assistance in their academics or future career plans. The recent pandemic that has swept the nation has led the college to implement swift changes to the delivery of the curriculum. Now more than ever, the bond that students share with the faculty has been vital in maintaining a semblance of familiarity.

The college's history shows that it has withstood and overcome various challenges since it opened its doors to eager students in 1945. It is an institution that prides itself on serving its community, students, and the optometric profession. Graduates carry forth these values with them and several have gone on to lead the profession as president of the American Optometric Association such as Charles W. McQuarrie, OD (1977), Larry D. DeCook (1995), J. Patrick Cummings (2002), and Dori M. Carlson, OD (2011). ${ }^{2}$

\section{In the offing}

Pacific University College of Optometry's mission-driven 
history and resourcefulness has contributed to its excellence and reputation. The college aims to continue working with industry to build a model using the current database for improving its clinical services and clinical education. ${ }^{13}$ Exciting research projects are ongoing and will continue in the fields of contact lenses, myopia control, vision therapy and traumatic brain injury. "Graduate education is a changing and challenging landscape. The Vision Science Graduate programs have brought lively impacts to our college on cultural variation as well as research productivity and opportunities. Through constant curriculum updates, my hope is to utilize our unique strengths in many areas of eye care and industrial vision research to prepare graduates with skills for a range of academic and non-academic career pathways," says Dr. Yu-Chi Tai, the director of Vision Science Graduate Program. In April 2020, the Chinese Ministry of Education approved a collaboration between Shandong University of Traditional Chinese Medicine and PUCO and efforts are underway to offer undergraduate, graduate degree programs and continuing educational workshops in China.

The college continuously strives to develop novel ways of diagnosing and treating eye conditions in collaboration with its international peers. ${ }^{15}$ Now, it is even more important than ever to nurture those passions and keep the doors of the college open to innovation and inspiration. This all began in 1945, when several individuals decided to plant the college's roots in Forest Grove. Pacific's trajectory of adaptability and genuine motivation for excellence in the profession assures its future will add to its interesting evolution.

\section{References}

1. The Oregon Optometrist. NovemberDecember,1970;37(6):1-7.

2. Bleything W. Pacific University College of Optometry. The Oregon Encyclopedia. March 18, 2018. https:// oregonencyclopedia.org/articles/pacific_university_ college_of_optometry/\#.XzSY2xNKhsN.

3. Email communication with Dr. Willard Bleything, Professor Emeritus, Pacific University College of Optometry, July 20, 2020.

4. Email communication with Dr. Hannu Laukkanen, Professor Emeritus, Pacific University College of Optometry and Dr. Norman S. Stern, former Professor at Pacific University College of Optometry and Consultant at Kaiser Permanente, August 13, 2020.

5. Email communication with Ms. Linna Armstrong, Academic Programs Coordinator, Pacific University
College of Optometry, July 23, 2020.

6. Email communication with Dr. Lorne Yudcovitch, Professor, Pacific University College of Optometry, August 1, 2020.

7. Email communication with Dr. James Kundart, Professor, Pacific University College of Optometry and Dr. Anne E Hogan, Associate Professor, Pacific University School of Audiology, August 2, 2020.

8. EyeSmile Outreach Program Overview, Pacific University College of Optometry, 2019-2020.

9. Optometry Community Outreach, Pacific University College of Optometry. https://www.pacificu.edu/ academics/colleges/college-optometry/academicprograms/optometry-od/optometry-communityoutreach

10. Lang J. College of Optometry Named School of the Year by National Optometric Association. Pacific University. July 27, 2018. https://www.pacificu.edu/about/media/ college-optometry-named-school-year-nationaloptometric-association.

11. AMIGOS Eye Care. Pacific University, http:// amigoseyecare.org/.

12. Personal communication over Zoom with Dr. Yu-Chi Tai, Director of Vision Science Graduate Programs, Pacific University College of Optometry, June 22, 2020.

13. CHAMP Study, Pacific University College of Optometry, https://www.pacificu.edu/academics/colleges/collegeoptometry/champ-study.

14. Goss DA. A History of M.S. and Ph.D. Programs Offered by Schools and Colleges of Optometry in North America. Optom Vis Sci 1993;70:616-621.

15. Email communication with Dr. Shun-Nan Yang, Director of Applied Vision Sciences Program and Vision Performance Institute, Pacific University College of Optometry, June 24, 2020. 